\title{
The double retro-aortic left renal vein
}

\author{
Dong-Soo Kyung ${ }^{1}$, Jae-Ho Lee ${ }^{1}$, Deuk-Yong Shin ${ }^{2}$, Dae-Kwang Kim ${ }^{1,3}$, In-Jang Choi ${ }^{1}$ \\ ${ }^{1}$ Department of Anatomy, Keimyung University School of Medicine, ${ }^{2}$ Department of Occupational and Environmental Medicine, Yeungnam University \\ Hospital, Yeungnam University College of Medicine, ${ }^{3}$ Institute for Medical Genetics, Keimyung University School of Medicine, Daegu, Korea
}

\begin{abstract}
The renal veins drain the kidney into the inferior vena cava and unite in a variable fashion to form the renal vein. The left renal vein is normally located in front of the aorta. However, the retro-aortic renal vein may course posterior to the aorta due to embryological developmental anomalies. During educational dissection, a rare variation of the left renal vein was found in a 66-year old male cadaver. The double retro-aortic renal veins coursed behind the aorta to drain into the inferior vena cava. The superior retro-aortic renal vein drained into the inferior vena cava at the lower border of the L2 vertebra, and the inferior retro-aortic renal vein drained into the inferior vena cava at the upper border of the L4 vertebra. Such a variant is rare, and is a clinically important observation which should be noted by vascular surgeons, oncologists, and traumatologists.
\end{abstract}

Key words: Renal veins, Variation, Retro-aortic

Received August 23, 2012; Revised September 28, 2012; Accepted October 25, 2012

\section{Introduction}

The renal veins connect the kidney to the inferior vena cava (IVC). They are usually singular to each kidney and located anterior to the aorta. However, because of its embryological development, the anatomy of the renal veins is variable. Various positioning of renal vein have been reported and the retro-aortic renal vein, located posterior to aorta, was also studied by many authors [1-6]. According to previous studies, the incidence of retro-aortic renal vein was reported to be $0.6-3.7 \%$ [1-6]. Even though, retro-aortic vein is the common venous variation, it is usually clinically silent. Therefore, it usually remains unnoticed unless discovered accidently during operation or diagnosis.

Many diagnostic and therapeutic procedures have been carried out in the renal vein and kidney, including venography

\footnotetext{
Corresponding author:

In-Jang Choi

Department of Anatomy, Keimyung University School of Medicine, 1095 Dalgubeol-daero, Dalseo-gu, Daegu 704-701, Korea

Tel: +82-53-580-3831, Fax:+82-53-580-3835, E-mail: ijchoi@dsmc.or.kr *Dong-Soo Kyung and Jae-Ho Lee contributed equally to this work.
}

and renal transplantation [7]. In addition, retro-aortic renal vein variation has a deep association with renovascular aneurysm, varicocele, inguinal or flank pain, and hematuria [1, $3,8,9]$. Therefore, retro-aortic renal vein has been the focus of clinicians as well as anatomists.

In the present report, the case of a double retro-aortic left renal vein is described. This variation is rare and has not been reported by dissection. The embryological and clinical significance of this variation are also discussed.

\section{Case Report}

Variation in the left renal vein was observed in the 66-yearold Korean male cadaver during educational dissection. The abdominal cavity was opened and abdominal viscera were systemically removed. The renal veins were identified and were traced from the hilum of the kidney to the IVC.

Two left renal veins, instead of coursing anterior to the aorta, passed behind it to drain into the IVC, therefore, these veins were defined as retro-aortic left renal veins (RA-LRV). The two RA-LRVs were defined as superior retro-aortic left renal vein (SRA-LRV) and an inferior retro-aortic left renal vein (IRA-LRV) according to their anatomical position (Fig. 1). The small SRA-LRV drained into the IVC horizontally at

\section{Copyright (c) 2012. Anatomy \& Cell Biology}

This is an Open Access article distributed under the terms of the Creative Commons Attribution Non-Commercial License (http://creativecommons.org/licenses/by-nc/3.0/) which permits unrestricted non-commercial use, distribution, and reproduction in any medium, provided the original work is properly cited. 
the lower border of the L2 vertebra, and IRA-LRV was passed obliquely downwards and drained into the IVC at the upper border of the L4 vertebra. The diameters of the SRA-LRV and IRA-LRV were $1 \mathrm{~cm}$ and $2.3 \mathrm{~cm}$, respectively. The left testicular vein was accompanied by the left testicular artery and drained into the bifurcation of the left main renal vein. The left suprarenal vein passed obliquely downwards and drained into left renal vein. Other arteries and veins showed a normal course.

\section{Discussion}

We have described the case of two RA-LRV which drained into the IVC at the L2 vertebra and L4 vertebra, respectively. The retro-aortic left renal vein has been studied by many authors [1-6], and its prevalence is presented in Table 1. Among various authors, Hoeltl et al. [2] classified retro-aortic renal veins as two main types, according to the obliteration type of embryonic renal venous collar. Retro-aortic left renal vein type I was developed by the persistence of the left sub-supracardinal anastomosis, the intersupracardinal anastomosis, and the left dorsal renal vein. Type II was developed by the persistence of the left subsupracardinal anastomosis and the supracardinal vein. Hoeltl et al. [2] reported that the frequency of type 1 and type 2 was $0.56 \%$ (2/354) on autopsy. On computed tomography (CT), type 1 and type 2 were found in $0.26 \%(12 / 4,520)$ and $0.38 \%$ $(17 / 4,520)$, respectively [2]. The present case showed type 1 and type 2 retro-aortic renal veins together and its frequency was extremely rare.
Two occurrences of retro-aortic renal veins are rare, however, similar cases have been observed by many authors. Koc et al. [9] observed this anomaly, not on cadaver, but on $\mathrm{CT}$, and it was suggested that this condition may be associated with left-sided pelvic congestion syndrome. In the case observed by Anjamrooz et al. [10], the patterns of the two retro-aortic renal veins were similar, however the left testicular vein joined the main renal vein. The left testicular vein in the present case drained into the bifurcation of the left main renal vein. Senecail et al. [7] also reported a similar case with a partially bifid and retro-aortic left renal vein by dissection. However, this variation was a bifid form of the renal vein only, which appearance was not considered as the persistence of circumaortic venous ring, as the embryogenesis of renal vein system. Therefore, this is the first report with double retro-aortic renal vein connected to the testicular vein.

To understand the development of this variation, the

Table 1. Frequency of retro-aortic renal vein anomalies according to various authors

\begin{tabular}{lllc}
\hline \multicolumn{1}{c}{ Reference } & Type & Material & No. (\%) \\
\hline Reed et al. [5] & RA-LRV & CT & $8 / 433(1.8)$ \\
Hoeltl et al. [2] & RARV & CT & $29 / 4,520(0.6)$ \\
& RARV & Operation & $6 / 215(2.8)$ \\
& RARV & Dissection & $4 / 354(1.1)$ \\
Martinez-Almagro et al. [4] & RA-LRV & CT & $4 / 170(2.4)$ \\
& RA-LRV & Dissection & $2 / 116(1.7)$ \\
Trigaux et al. [6] & RARV & CT & $38 / 1014(3.7)$ \\
Arslan et al. [1] & RA-LRV & CT & $19 / 1125(1.7)$ \\
Karazincir et al. [3] & RA-LRV & US & $3 / 137(2.2)$ \\
\hline
\end{tabular}

RA-LRV, retroaortic left renal vein; CT, computed tomography; RARV, retroaortic renal vein; US, ultrasonography.
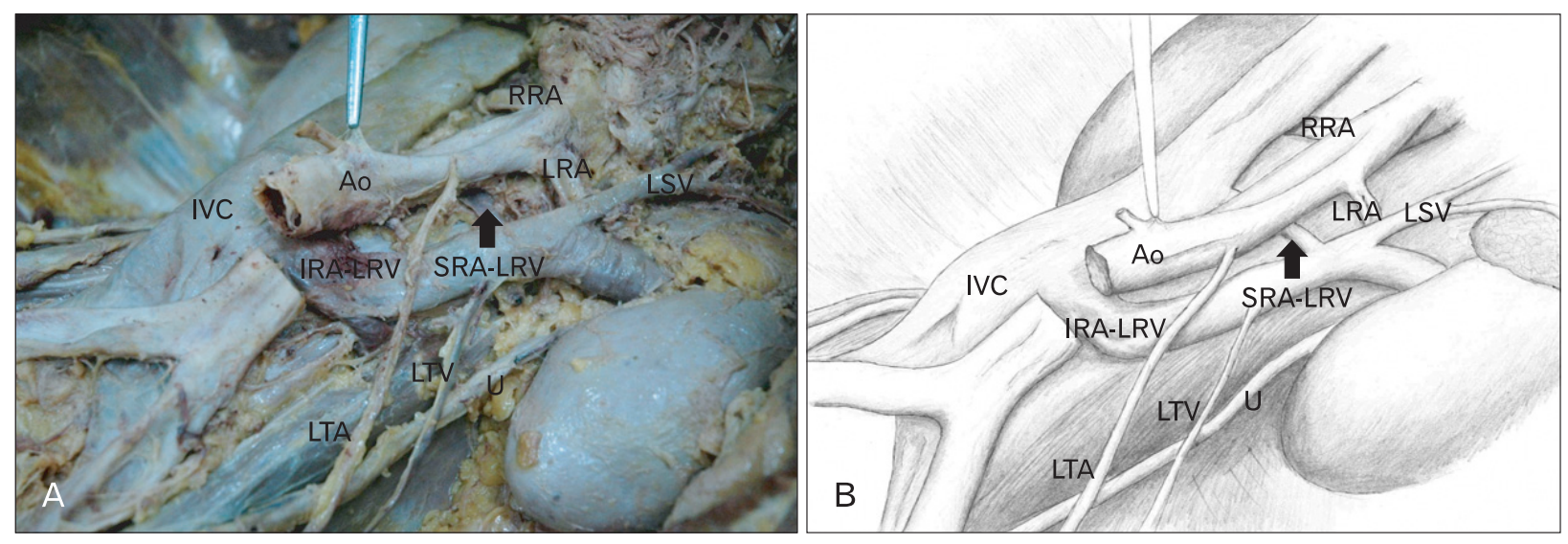

Fig. 1. Photograph (A) and schematic drawing (B) showing double retro-aortic left renal vein. Two retro-aortic left renal veins (SRA-LRV and IRA-LRV) were drained into inferior vena cava. Ao, aorta; IRA-LRV, inferior retro-aortic left renal vein; IVC, inferior vena cava; LRA, left renal artery; LSV, left suprarenal vein; LTA, left testicular artery; LTV, left testicular vein; RRA, right renal artery; SRA-LRV, superior retro-aortic left renal vein; $\mathrm{U}$, ureter. 
A

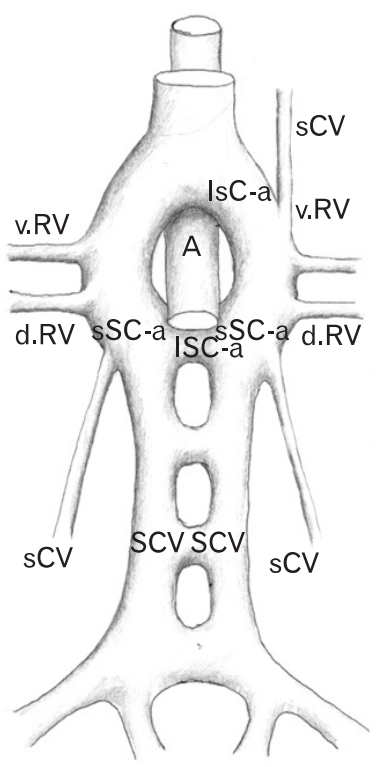

B

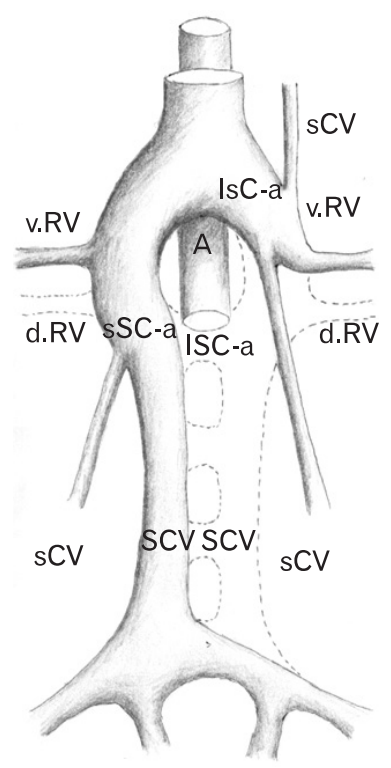

C

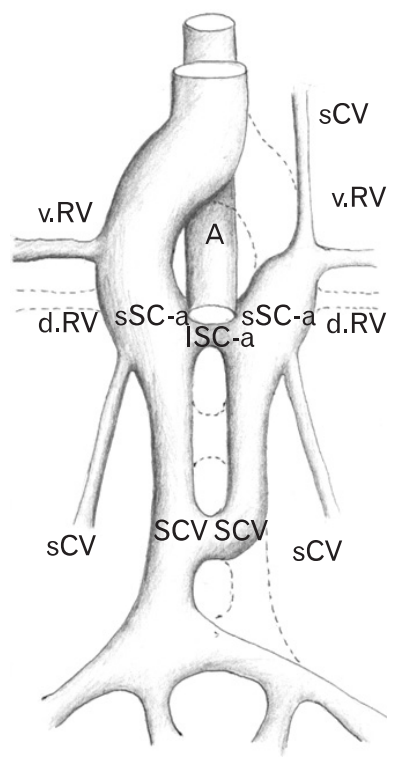

Fig. 2. Drawing of the development of the renal vein. (A) Renal venous collar at 8 week of embryogenesis. (B) Normal development of renal veins in adult. (C) Abnormal development of renal vein in present report. A, aorta; d.RV, dorsal renal vein; IsC-a, intersubcardinal anastomosis; ISC-a, intersupracardinal anastomosis; $\mathrm{s} \mathrm{CV}$, subcardinal vein; SCV, supracardinal vein; sSC-a, subsupracardinal anastomosis; v.RV, ventral renal vein. mbryogenesis of the renal vein system should be considered. At 8 weeks of embryogenesis, a circumaortic venous ring (so-called 'renal collar') is developed completely (Fig. 2A). As development procedes, certain predestined parts of this primitive venous drainage obliterate, and normal development of renal vein in adult is completed (Fig. 2B). In the present case, the left sub-supracardinal anastomosis, the inter-supracardinal anastomosis, the left ventral renal vein, and left supracardinal vein persisted. The left dorsal renal vein and the inter-subcardinal anastomosis were obliterated. This embryological approach can clearly explain the development of SRA-LRV and IRA-LRV in the present case. Persistence of the left sub-supracardinal anastomosis and the intersupracardinal anastomosis became SRA-LRV. Persistence of the sub-supracardinal anastomosis on the left side and the left supracardinal vein became IRA-LRV (Fig. 2C).

In the present report, a rare case with double retro-aortic left renal vein was described. Our report may contribute to the expansion of anatomic knowledge in reno-vascular structure because of its rarity. Awareness of venous variations in kidney may be useful because its variation could enhance iatrogenic injuries or complications during several invasive procedures and influence hemodynamic problems with unexplained symptoms $[1,3,8]$.

\section{References}

1. Arslan H, Etlik O, Ceylan K, Temizoz O, Harman M, Kavan M. Incidence of retro-aortic left renal vein and its relationship with varicocele. Eur Radiol 2005;15:1717-20.

2. Hoeltl W, Hruby W, Aharinejad S. Renal vein anatomy and its implications for retroperitoneal surgery. J Urol 1990;143:110814.

3. Karazincir S, Balci A, Görür S, Sumbas H, Kiper AN. Incidence of the retroaortic left renal vein in patients with varicocele. J Ultrasound Med 2007;26:601-4.

4. Martinez-Almagro A, Almenar Garcia V, Martinez Sanjuan V, Hernandez Gil de Tejada T, Lorente Montalvo P. Retroaortic left renal vein: a report of six cases. Surg Radiol Anat 1992;14:361-6.

5. Reed MD, Friedman AC, Nealey P. Anomalies of the left renal vein: analysis of 433 CT scans. J Comput Assist Tomogr 1982;6:1124-6.

6. Trigaux JP, Vandroogenbroek S, De Wispelaere JF, Lacrosse M, Jamart J. Congenital anomalies of the inferior vena cava and left renal vein: evaluation with spiral CT. J Vasc Interv Radiol 1998;9:339-45.

7. Senecail B, Bobeuf J, Forlodou P, Nonent M. Two rare anomalies of the left renal vein. Surg Radiol Anat 2003;25:465-7.

8. Nam JK, Park SW, Lee SD, Chung MK. The clinical significance of a retroaortic left renal vein. Korean J Urol 2010;51:276-80.

9. Koc Z, Ulusan S, Tokmak N, Oguzkurt L, Yildirim T. Double retroaortic left renal veins as a possible cause of pelvic congestion syndrome: imaging findings in two patients. Br J Radiol 2006;79:e152-5.

10. Anjamrooz SH, Azari H, Abedinzadeh M. Abnormal patterns of the renal veins. Anat Cell Biol 2012;45:57-61. 